\title{
INFECTIOUS STUNTING SYNDROME ASSOCIATED WITH DISTURBANCES OF MINERAL METABOLISM AND BONE DEVELOPMENT IN BROILER CHICKENS
}

\author{
G. SÁLYI* and R. GLÁVITS \\ Central Veterinary Institute, H-1581 Budapest, P.O. Box 2, Hungary \\ (Received October 20, 1998; accepted January 12, 1999)
}

\begin{abstract}
On a broiler farm with a rearing capacity of about 200,000 chickens, a disease characterised by growth retardation, variability in chick size, 'leg weakness', diarrhoea and increased mortality at 3 weeks of age occurred repeatedly, in several successive broiler flocks. Gross and histopathological findings were dominated by widening of the hypertrophic and ossification layers of the physes of long bones as well as by thickening, unevenness and defective calcification of the cartilage trabeculae. In the parathyroid gland, vacuolar degeneration of the cytoplasm of glandular epithelial cells, connective tissue proliferation and, here and there, cyst formation were seen. Additional findings included severe cerebellar oedema and neuronal degeneration. The pancreatic, myocardial and intestinal changes typical of infectious stunting syndrome (ISS) occurred only in a mild form. Fourweek-old chickens exhibiting 'leg weakness' had significantly lower blood inorganic phosphate concentration and tibial ash content as compared to healthy chickens. The disease was successfully transmitted by oral administration of small intestinal homogenate from affected chickens. In a second experiment, however, the disease could not be transmitted with intestinal homogenate sterilized by irradiation. Large doses of vitamin $\mathrm{D}_{3}$ reduced the rate of growth retardation and defective calcification of bones. The digestive enzyme activities of the pancreas and small intestinal mucosa of 'infected' chickens were decreased as is typical of ISS.
\end{abstract}

Key words: Infectious stunting syndrome, chicken, bone abnormalities, disturbances of mineral metabolism, pathology, transmission experiments

Disease entities of young chickens characterised by growth retardation, ossification disturbances, and uneven growth of chicks throughout the flock may be caused by a wide variety of aetiological factors. In addition to certain metabolic and deficiency diseases, such clinical manifestations can be caused in broiler chickens (Nelson et al., 1982; Reece et al., 1984; Bitay et al., 1986) and turkeys (McLoughlin et al., 1987; Angel and Sell, 1990; Perry et al., 1991a,b,c) by syndromes designated as malabsorption syndrome, infectious stunting syn-

*E-mail: salyi@indigo2.oai.hu; Fax: (36-1) 252-8444 
drome (ISS) and described under various other names (pale bird syndrome, 'helicopter disease' and recently 'enteric disease complex') in many parts of the world. The aetiology of these conditions remains obscure but they have been found to be transmissible from diseased to healthy birds. Numerous viruses have been suggested to play an aetiological role, but so far the syndrome could not be experimentally reproduced in its entirety with any virus isolate.

The dominant signs include growth retardation, unevenness in chick size throughout the flock and defective, abnormal feathering. The occurrence of expressed disturbances of mineral metabolism and ossification disorders in connection with ISS has not been reported in Hungary either by Bitay et al. (1986) or by others.

Several reports (Kouwenhoven et al., 1978; Page et al., 1980; Ruff, 1982; Reece et al., 1984) mention locomotor and ossification disturbances appearing simultaneously with the development of infectious stunting. Some of the authors first describing the syndrome laid such great emphasis on the severity of that ossification disturbance, attributed to osteoporosis, that they even gave it a separate name, 'brittle bone disease' (Vertommen et al., 1980; Van der Heide et al., 1981). In flocks affected with infectious stunting, the above authors and other researchers often observed femoral head necrosis, detachment of the articular cartilage covering the femoral head, or detachment of the femoral head itself (Page et al., 1980; Vertommen et al., 1980; Van der Heide et al., 1981). 'Rickets-like' changes (Vertommen et al., 1980; Bergs and Goedegebuure, 1982; Reece et al., 1984) or lesions indicative of osteodystrophy (Kouwenhoven et al., 1978; Reece and Frazier, 1990) or dyschondroplasia (Vertommen et al., 1980; Reece et al., 1984) have also been observed.

This paper reports on the occurrence in Hungary of a form of infectious stunting syndrome which is transmissible to healthy chickens and manifests itself in ossification disturbances and lesions of the parathyroid gland. Experimental studies on the pathogenesis of this disease entity are also presented.

\section{Field case}

A disease accompanied by growth retardation, ossification disturbances and mortality was observed in 2- to 3-week-old broiler chickens on a multiplehouse farm with a rearing capacity of about 200,000 chickens. At 2-3 weeks of age, the chickens showed variation in size, slightly decreased feed consumption, and diarrhoea. The number of deaths per day rose to multiples of the acceptable level, then after about 10 days it decreased. Affected chickens exhibited 'leg weakness' and some of them showed slight head tremors and, before death, recumbency and spasmodic wriggling with legs stretched backwards. The affected 
chickens belonged to placements made at different times and had originated from different breeder flocks and even from different hatcheries. They consumed feed obtained from two different suppliers. Despite these differences, the impairment of production results, the mortality rate, the clinical signs and the severity of lesions in the organs were highly similar in the different broiler houses.

Gross and histopathological examinations showed thickening of the proventricular wall, small intestinal catarrh, widening of the epiphyseal cartilage (Fig. 1) of the long bones (femur and tibia), delayed resorption and defective calcification of the epiphyseal cartilaginous tissue, severe cerebellar oedema and mild cerebral oedema associated with neuronal degeneration or necrosis, focal lympho-histiocytic infiltration among the acini of the pancreas and, in a few chickens, lympho-histiocytic myocarditis, acute liver dystrophy, and renal degeneration (tubulonephrosis). In three houses, the development of the so-called ascites syndrome was recorded in the majority of chickens that died at 5-7 weeks of age.

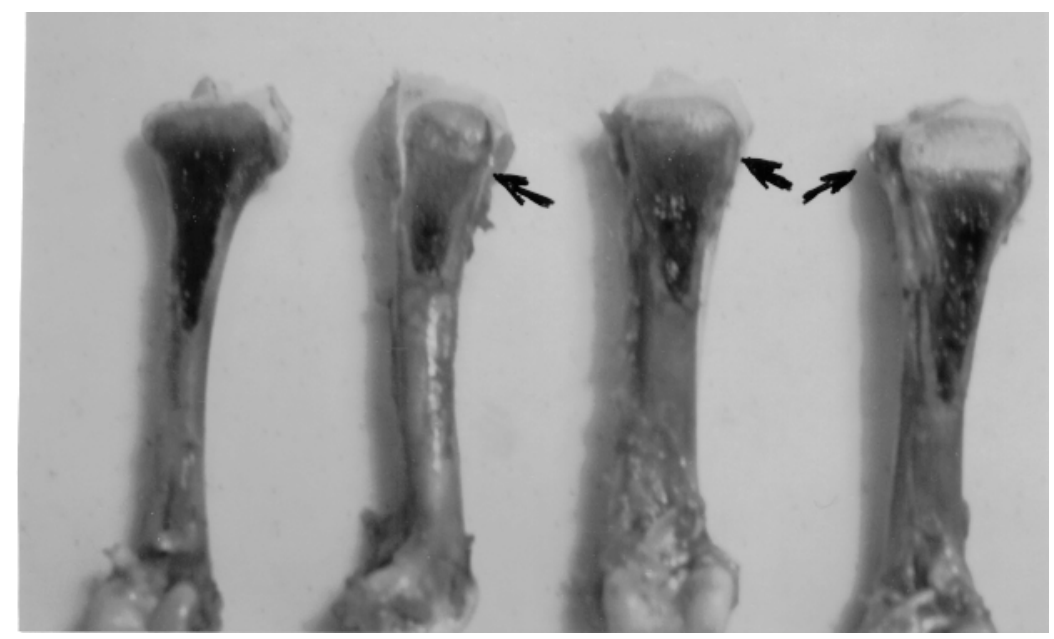

Fig. 1. The tibia of chickens with 'leg weakness' (the three bones on the right) shows widening of the epiphyseal cartilage $(\uparrow)$ and defective resorption as compared to the healthy control (left)

The results of feed analyses and mycotoxicological examinations, which revealed occasional slight contamination with the fusariotoxins F-2 and DON, could not account for the losses observed.

While severe losses did not occur during the rearing of the flocks immediately succeeding the affected flocks, the subsequent placements were affected by the same problems as the first one, i.e. impaired growth and variation in chick size. At 20 days of age, there was a substantial increase in chick mortality rate in the two houses stocked with a time difference of one week. The mortality rate 
followed a two-peaked curve (with daily losses of nearly $1 \%$ in the two peaks) and started to decrease only about two weeks later.

Ten dead chickens submitted to our institute from this latter flock on Day 31 of rearing, 8 'affected' live chickens showing diarrhoea and leg weakness, and 5 symptomless 'control' chickens originating from the same flock were examined. All affected birds showed morphological signs of ossification disturbances of varying severity (widening and unevenness of the cartilaginous ossification zone, suppleness of the long bones, brittleness of the femoral head, pliancy of the beak and, occasionally, deformation of the sternum). Histopathological examination demonstrated expressed cerebellar oedema associated with neuronal necrosis in several chickens and incipient acute liver dystrophy in a few birds. Additional findings included renal degeneration (tubulonephrosis), mild circumscribed lympho-histiocytic myocarditis, and lympho-histiocytic infiltration in the mucous membrane of the major airways. The pancreas, the bursa of Fabricius, the thymus and the bone marrow were histologically normal.

No virus particles were detected by electron microscopic examination of the pellet obtained by ultracentrifugation of the small intestinal and pancreatic homogenate. Serological tests aimed at detecting antibodies to reoviruses in sera of the live chickens were also negative.

To obtain data on the pathogenesis, some clinicochemical parameters of the blood of 31-day-old 'affected' and 'healthy' chickens were determined and compared (Table 1). The biggest differences were obtained in serum calcium concentration but even more so in serum inorganic phosphate $(\mathrm{P})$ level. The lower average ash content (expressed for fat-free dry matter content) of the tibia of affected chickens was also remarkable (Table 1). Serum Ca and inorganic $\mathrm{P}$ levels and tibial ash content, in line with the gross pathological findings, were a good indicator of the disturbed mineral metabolism. The slightly elevated haematocrit value, haemoglobin, uric acid and albumin concentration of the blood of 'affected' chickens with respect to the controls can probably be explained by the inadequate feed and drinking water consumption attributable to impaired movement, as well as by diarrhoea and the consequent exsiccosis. Serum vitamin E content was below the desirable level $(\sim 5.0 \mu \mathrm{mol} / 1)$ in both groups, and 'affected' chickens showed substantial individual variation in that parameter.

Examination of dead chickens submitted 5 days later gave similar results. The severity of the ossification disturbance was indicated by the finding that during preparation of the carcase for necropsy the femoral head or the articular cartilage covering it became detached in most cases.

Also in this case, analysis of the feeds did not reveal any quality defects (mycotoxin contamination, abnormal $\mathrm{Ca}, \mathrm{P}$ or $\mathrm{Na}$ content, etc.) that could be brought into connection with the syndrome. 
As the feed analyses did not reveal quality defects and since other farms using diets from the same supplier and batch did not experience similar problems, the suspicion arose that an infectious agent might be involved in the aetiology of the condition. In order to prove or refute this assumption, a transmission experiment was conducted using small intestinal and pancreatic homogenates from the chicken carcases.

\section{Table 1}

Clinicochemical parameters of the blood, serum and tibia of 'affected' chickens showing leg weakness and of healthy chickens from the field case of infectious stunting

\begin{tabular}{lccc}
\hline & Affected $(\mathrm{n}=7)$ & Healthy $(\mathrm{n}=5)$ & $*$ \\
\hline Haematocrit, $/ 1 \mathrm{l}$ & $0.33 \pm 0.025^{+}$ & $0.30 \pm 0.02$ & $*$ \\
Haemoglobin, $\mathrm{mmol} / \mathrm{l}$ & $5.47 \pm 0.70$ & $4.69 \pm 0.20$ & $*$ \\
Calcium, $\mathrm{mmol} / \mathrm{l}$ & $2.38 \pm 0.16$ & $2.54 \pm 0.22$ & $*$ \\
Inorganic $\mathrm{P}, \mathrm{mmol} / \mathrm{l}$ & $1.48 \pm 0.36$ & $304 \pm 95$ & \\
Uric acid, $\mu \mathrm{mol} / \mathrm{l}$ & $528 \pm 211$ & $3.29 \pm 0.84$ & $*$ \\
Vitamin E, $\mu \mathrm{mol} / \mathrm{l}$ & $2.97 \pm 1.60$ & Healthy $(\mathrm{n}=4)$ & \\
\hline
\end{tabular}

${ }^{+}$Mean \pm standard deviation. The asterisk $\left(^{*}\right)$ denotes a significant difference $(\mathrm{P}<0.05)$

\section{Materials and methods}

\section{Experiment I}

Experimental design. Two groups, each containing 30 Arbor Acres broiler cockerel chicks kept in wire cages in the same air-space, were fed a broiler starter diet and offered drinking water from automatic drinkers ad libitum from one day of age.

With the help of a flexible oesophageal tube, $0.6 \mathrm{ml}$ small intestinal and pancreatic homogenate was administered into the crop of chicks in the 'infected' group at 2 and then at 4 days of age. The 'control' chicks were left untreated.

The chickens were weighed individually on Days 1, 7, 11, 16, 24 and 30 of the experiment. On Days 15, 18, 24 and 30 of the experiment, 6, 4, 6 and 10 'control' chickens and 7, 4, 7 and 11 'infected' chickens, respectively, were selected at random and killed by bleeding for gross and histopathological examination and biochemical tests.

Preparation of homogenate. The small intestine and pancreas of chickens that died at 36 days of age in the field case were homogenised with saline in a ratio 
of 2:1 using a high-speed blender. Coarse particles remaining in the homogenate were centrifuged, and the supernatant was stored frozen $\left(\right.$ at $\left.-18^{\circ} \mathrm{C}\right)$ until used.

Histological procedure. Pieces from the liver, kidneys, brain, heart, pancreas, duodenum, tibia, thymus and bursa of Fabricius of chickens bled at the above times in the two groups, together with their entire thyroid, parathyroid and adrenal glands were fixed in $10 \%$ buffered $(\mathrm{pH}$ 7.2) formalin solution and processed by the paraffin embedding or the freezing method. Bone samples had been decalcified previously. The sections were stained with haematoxylin and eosin. Sections prepared from the liver, kidneys and adrenals were also stained by the Fat Red procedure while parathyroid glands showing pathological alterations by van Gieson's method.

Clinicochemical methods. Blood plasma samples obtained by centrifugation from blood samples taken into heparinised tubes were stored at $-18{ }^{\circ} \mathrm{C}$ until assayed. The $\mathrm{Ca}$ and $\mathrm{Mg}$ concentrations of plasma samples were determined by atomic absorption spectrophotometry (Pye Unicam PU 9200X apparatus), their phosphate, uric acid and triglyceride content, AST activity (Reanal test) and digestive enzyme activities by photometry (Szabó et al., 1989), 25-hydroxy-D ${ }_{3}$ vitamin content by high-performance liquid chromatography (HPLC), while the concentrations of vitamins $\mathrm{A}$ and $\mathrm{E}$ by a spectrofluorometric method (Sándor and Csörögi, 1989).

To determine their ash content, the bones were cooked in boiling distilled water for $10 \mathrm{~min}$, then the remnants of muscles, tendons and articular cartilage were removed. The bones were dried and their lipids were extracted with diethyl ether in a Soxhlet apparatus. The bones dried to constant weight were weighed, incinerated in an oven of $550{ }^{\circ} \mathrm{C}$ temperature for $5 \mathrm{~h}$, and the resulting ash was weighed.

\section{Experiment II}

The breed, age, housing, feeding and method of infection of the chickens used in Experiment II were the same as in Experiment I. The chickens were divided into four groups: Group 1: control (as in Experiment I); Group 2: 'infected' (as in Experiment I); Group 3: treated with sterilized intestinal homogenate $(0.6 \mathrm{ml}$ on each occasion); Group 4: 'infected' group (as Group 2) but fed a diet supplemented with vitamin $\mathrm{D}_{3}$. Part of the intestinal homogenate (i.e. that used for treating chickens of Group 3) was sterilized by gamma-irradiation with a radiation dose of 5.0 Mrad in a Noratron type apparatus under continuous cooling. The vitamin $\mathrm{D}_{3}$ content of the diet fed to Group 4 was increased to five times the level specified in the formula $(2910 \mathrm{IU} / \mathrm{kg})$ by supplementation with vitamin $\mathrm{D}_{3}$.

The chickens were weighed on Days 1, 5,13, 18 and 22. On Days 5, 7, 13, 18 and 22 of the experiment 6 chickens in each group were killed for gross and 
histopathological examinations and 5 chickens in each group for virological examinations and biochemical tests.

Statistical analysis. Statistical evaluation of parameters that could be expressed in numerical terms was done by Student's $t$-test.

\section{Results}

\section{Experiment $I$}

Clinical observations. Infected chickens showed apparent growth retardation already at one week old. Later this became even more pronounced, and substantial variability in body mass developed (Table 2).

Table 2

Body mass $(\mathrm{g})$ of chickens treated with a crude inoculum from the 'affected' chickens and of the control chickens (Experiment I)

\begin{tabular}{rlllll}
\hline Day & $\mathrm{n}$ & Infected & $\mathrm{n}$ & Control \\
\hline 1 & 30 & $43.9 \pm 5.4$ & 30 & $40.9 \pm 6.5$ & $*$ \\
7 & 30 & $127.1 \pm 15.7$ & 30 & $154.5 \pm 13.5$ & $*$ \\
11 & 29 & $152.1 \pm 24.2$ & 30 & $187.2 \pm 15.7$ & $*$ \\
16 & 22 & $224.6 \pm 44.2$ & 24 & $356.9 \pm 34.0$ & $*$ \\
24 & 18 & $560 \pm 93$ & 20 & $727 \pm 64$ & $1028 \pm 64$ \\
30 & 11 & $880 \pm 104$ & 14 & & $*$ \\
\hline
\end{tabular}

The asterisk $(*)$ denotes a highly significant difference $(\mathrm{P}<0.001)$

At $8-11$ days of age about $25 \%$ of the infected chickens excreted yellowish-brown, homogeneous droppings of thin mustard consistency, and the area around the vent was contaminated with dried faecal matter. On Day 8, two 'infected' chickens were seen to move clumsily, but this sign disappeared after 1-2 days. Of the experimental chickens, a single 'infected' bird died on Day 11. (The gross pathological examination did not reveal noteworthy lesions.)

The feathering of the stunted chickens corresponded to their developmental status, and the imperfect development of feathers (primarily of the wing feathers) typical of malabsorption syndrome (the so-called 'helicopter' disease) could not be observed. The control chickens were free of disease symptoms and had undisturbed body mass gain (Table 2).

Gross pathological findings. The tibia of 'infected' chickens was markedly easier to bend or slice. The epiphyseal cartilage was widened in several chickens. No gross lesions were seen in other organs. 
Histopathological changes. As compared to the control (Fig. 2), the parathyroid gland of infected chickens killed on Day 15 or Day 18 showed the formation of cytoplasmic vacuoles in, and proliferation of fibrocytes and connective tissue fibres among the glandular epithelial cells (Fig. 3), here and there the atrophy of these cells and rarely the formation of cysts (Fig. 4). Compared to the control (Fig. 5), in the so-called hypertrophic and ossification layer of the physis located at the epiphyseo-diaphyseal border of the tibia the cartilage trabeculae were of irregular shape and thickened (Fig. 6) and even showed signs of degeneration in some places (Fig. 7). These layers were wider but the rate of calcium salt deposition was lower than in the control chickens. The Purkinje cell layer of the cerebellum showed oedematous infiltration, while the small intestinal mucosa exhibited signs of enhanced glandular secretion, vacuolar degeneration of some epithelial cells and, as compared to the control, enhanced epithelial desquamation (Fig. 8). All other organs examined, including the bone marrow, were free of pathological alterations.
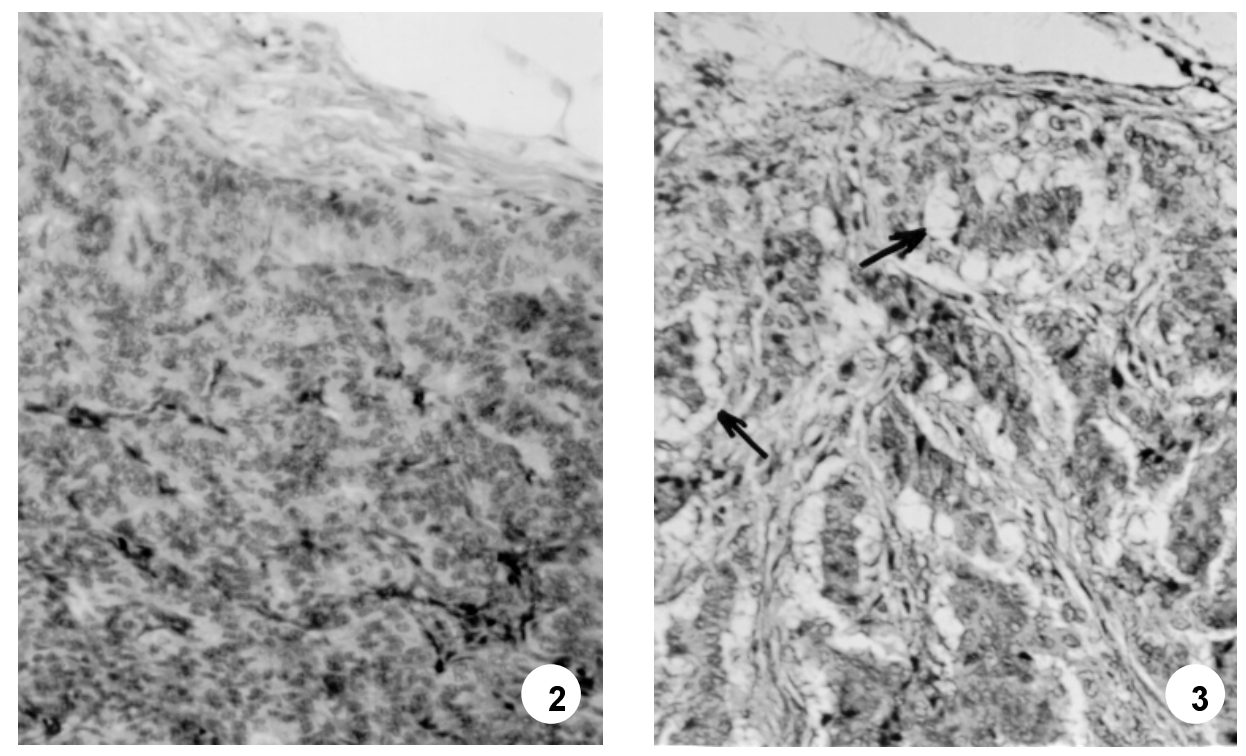

Fig. 2. Detail of the parathyroid gland of a healthy (control) chicken. The glandular epithelial cells are arranged in closely packed rows. Haematoxylin and eosin (H.-E.), $\times 90$

Fig. 3. Detail of the parathyroid gland of a chicken 'infected' with pancreatic and small intestinal homogenate from affected chickens showing the signs of 'leg weakness'. Note vacuolation of the cytoplasm of glandular epithelial cells $(\uparrow)$ and proliferation of the connective tissue fibres between the cell rows. H.-E., $\times 360$

When examining the organs of chickens killed on Day 24 and Day 30, the changes described above could be found only in a certain proportion of the birds and in a milder form. 


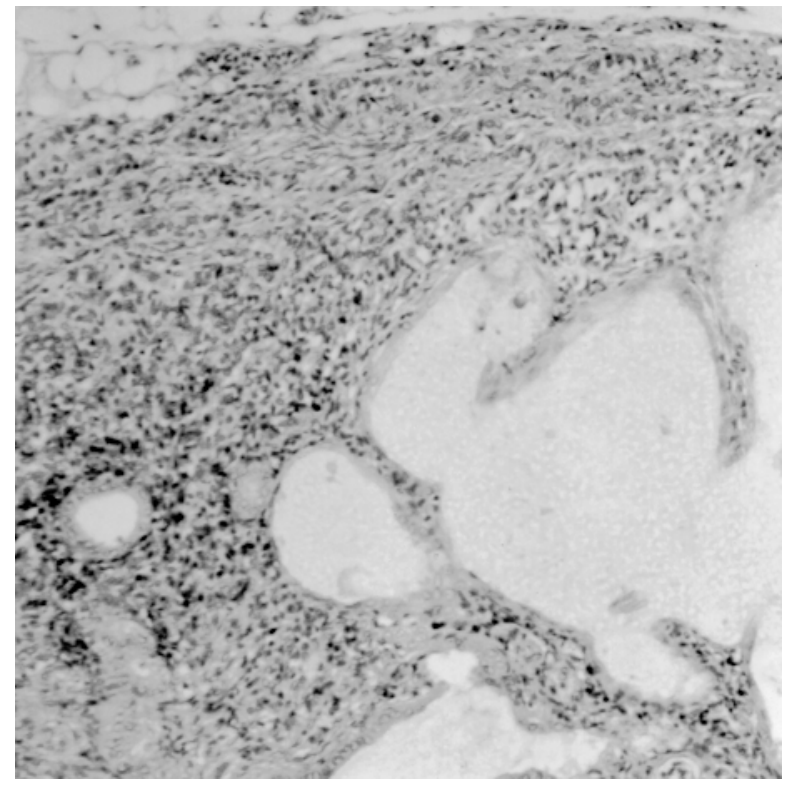

Fig. 4. Detail of the parathyroid gland of a chicken 'infected' with pancreatic and small intestinal homogenate. Note the cavity filled with exudate (cyst) and consequent atrophy of the glandular tissue. H.-E., $\times 40$
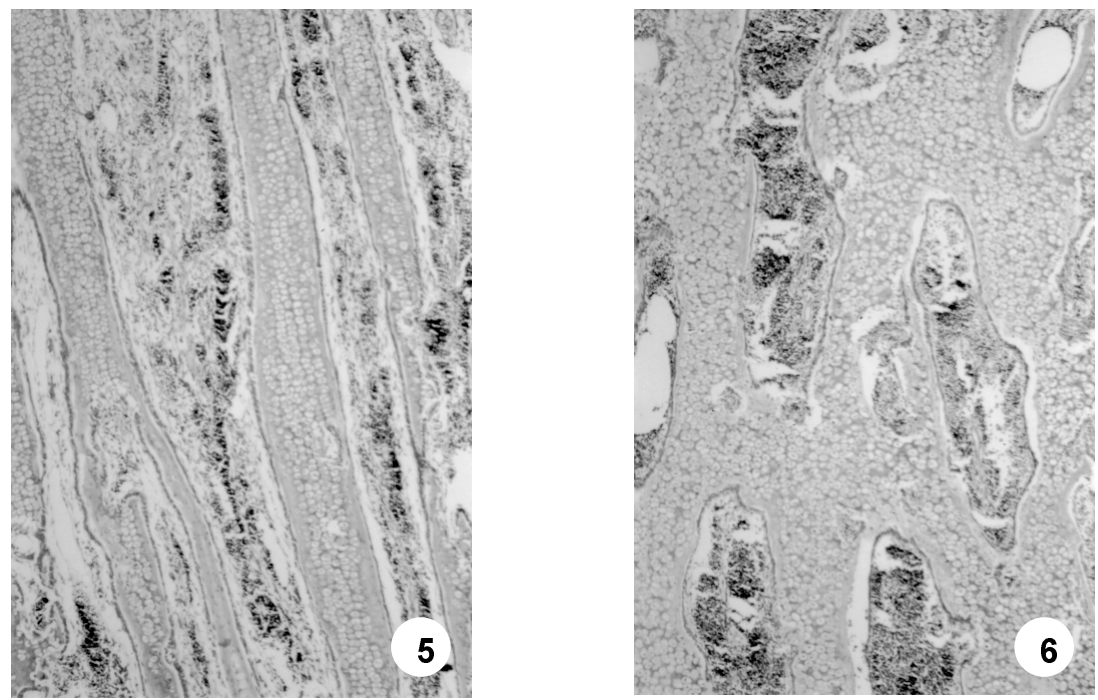

Fig. 5. Detail of the proximal epiphysis of the tibia of a healthy (control) chicken. The cartilage trabeculae in the so-called ossification layer are narrow and of normal shape. H.-E., $\times 60$ Fig. 6. Detail of the proximal epiphysis of the tibia of a chicken 'infected' with pancreatic and small intestinal homogenate. The cartilage trabeculae in the so-called ossification layer are widened and of irregular shape. H.-E., $\times 60$ 

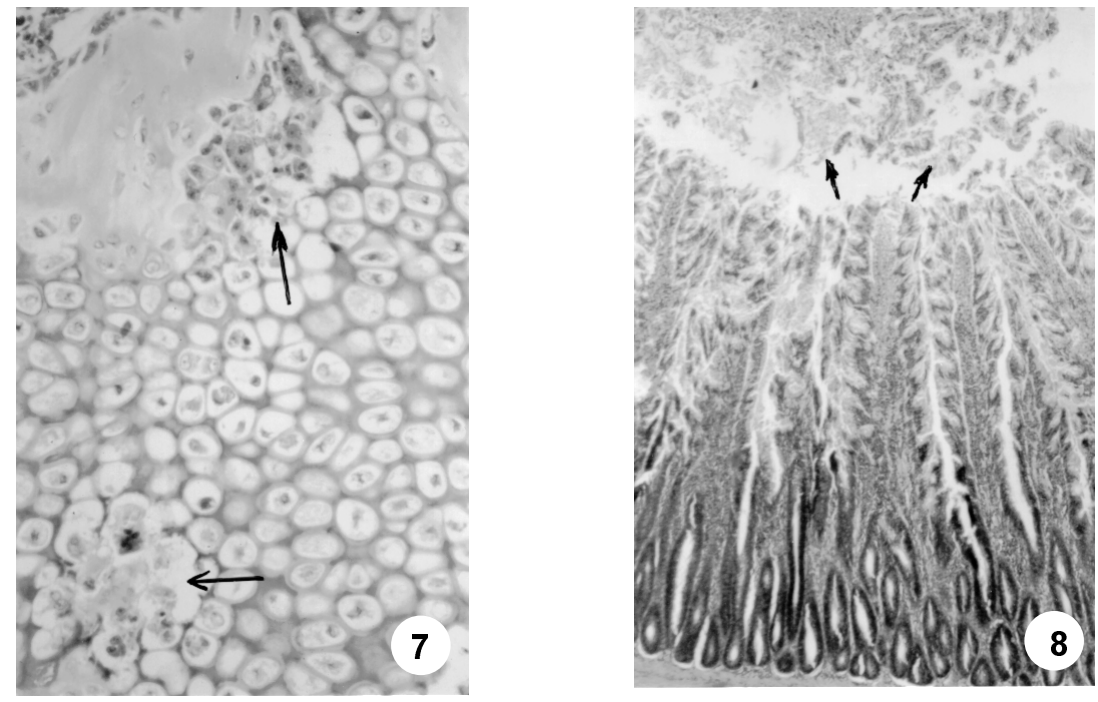

Fig. 7. Detail of Fig. 7 with 400-fold magnification. Morphological signs of degeneration $(\uparrow)$ (shrinking or lysis of the chondrocytes) can be observed in circumscribed areas of the cartilaginous tissue. H.-E., $\times 240$

Fig. 8. Detail of the small intestinal mucosa of a chicken 'infected' with pancreatic and small intestinal homogenate. Note desquamation of a proportion of the epithelial cells $(\uparrow)$. H.-E., $\times 60$

Clinicochemical results. The mean $\mathrm{Ca}$ and inorganic $\mathrm{P}$ concentrations of the blood samples are presented in Table 3. Blood inorganic P level of the infected chickens showed large individual variation and was significantly lower than in the control birds. That difference decreased but did not disappear by the end of the experiment. A similar though somewhat less marked difference was found in blood calcium content. No appreciable difference was found between the two experimental groups in plasma uric acid content and AST activity at any of the times studied. Mean plasma vitamin E content was relatively low (1.90 $\mu \mathrm{mol} / \mathrm{l})$ at 15 days of age, and did not differ between the two groups. Tibial ash content (expressed for fat-free tissue) was significantly lower in the infected chickens than in the controls at all times of examination (Table 3 ).

By electron microscopic examination of the intestinal content of chickens killed on Day 18, performed after ultracentrifugation and negative contrast staining, the presence of viruses could not be demonstrated.

\section{Experiment II}

Clinical observations. In addition to the differences seen in growth rate and feathering between, and also within, the experimental groups, around 2 weeks of age two of the infected chickens excreted faeces resembling mustard in both colour 
and consistency, which is considered to be typical of the syndrome. Four other chickens showed signs of transient 'leg weakness' that lasted for a few days.

Table 3

Blood plasma $\mathrm{Ca}$ and inorganic $\mathrm{P}$ levels and ash content of the defatted tibia in chickens 'infected' with the inoculum and in control chickens (Experiment I)

\begin{tabular}{|c|c|c|c|c|c|}
\hline Day & $\mathrm{n}$ & 'Infected' & $\mathrm{n}$ & Control & \\
\hline \multicolumn{6}{|c|}{$\mathrm{Ca}$ content $(\mathrm{mmol} / \mathrm{l})$} \\
\hline 15 & 7 & $2.27 \pm 0.26$ & 6 & $2.56 \pm 0.13$ & $*$ \\
\hline 24 & 7 & $2.42 \pm 0.30$ & 7 & $2.54 \pm 0.07$ & \\
\hline 30 & 11 & $2.51 \pm 0.17$ & 12 & $2.59 \pm 0.13$ & \\
\hline \multicolumn{6}{|c|}{ Inorganic $\mathrm{P}$ content $(\mathrm{mmol} / \mathrm{l})$} \\
\hline 15 & 7 & $1.41 \pm 0.31$ & 6 & $1.90 \pm 0.23$ & * \\
\hline 24 & 7 & $1.62 \pm 0.56$ & 7 & $2.15 \pm 0.27$ & * \\
\hline 30 & 11 & $2.39 \pm 0.27$ & 12 & $2.41 \pm 0.28$ & \\
\hline \multicolumn{6}{|c|}{ Bone ash content $(\%)$} \\
\hline 15 & 6 & $46.7 \pm 4.5$ & 6 & $52.8 \pm 1.5$ & * \\
\hline 24 & 7 & $48.9 \pm 5.6$ & 7 & $53.2 \pm 2.66$ & * \\
\hline 30 & 7 & $54.9 \pm 1.42$ & 7 & $52.4 \pm 2.02$ & * \\
\hline
\end{tabular}

The asterisk $(*)$ denotes a significant difference $(\mathrm{P}<0.05)$

Infected chickens had lower average body mass than the controls already on Day 5 of the experiments and subsequently at all weighing dates (Table 4). Apart from the value obtained on Day 5 , the body mass of control chickens did not differ significantly from that of chickens fed a diet supplemented with vitamin $\mathrm{D}_{3}$. Chickens treated with the inoculum sterilized by irradiation were heavier than those of the three other groups at all weighing dates except at the start of the experiment.

Gross and histopathological changes. The tibias of chickens originating from the infected group and killed on Days 12 and 17 were easier to bend and slice. The epiphyseal cartilage was widened in several chickens. The organs showed no pathological changes. In chickens fed a diet supplemented with vitamin $\mathrm{D}_{3}$ and in those treated with an inoculum sterilised by irradiation no bone abnormalities were found. By histopathological examination, on Days 12 and 17 the parathyroid gland, tibia, brain and small intestinal wall of chickens of the infected group showed changes similar to those observed in Experiment I. The above changes could also be observed in the parathyroid and small intestine of infected chickens fed a diet supplemented with vitamin $\mathrm{D}_{3}$, but the tibia was free of morphological alterations. On Days 12 and 17 the examined organs of the 
control chickens did not show changes. However, on Day 21 changes resembling those seen in the infected chickens were observed in the parathyroid, intestinal wall and tibia of 3 control chickens.

Table 4

Changes in body mass $(\mathrm{g})$ of chickens in Experiment II

\begin{tabular}{rcccc}
\hline Day & Control chickens & 'Infected' chickens & $\begin{array}{c}\text { Chickens treated } \\
\text { with irradiated } \\
\text { inoculum }\end{array}$ & $\begin{array}{c}\text { Chickens receiving } \\
\text { vitamin } \mathrm{D}_{3} \\
\text { supplementation }\end{array}$ \\
\hline 1 & $40.7 \pm 0.8^{\mathrm{a}}$ & $39.3 \pm 0.8$ & $40.6 \pm 0.8$ & $38.6 \pm 1.8$ \\
5 & $85.9 \pm 2.0^{\mathrm{a}}$ & $76.7 \pm 2.0^{\mathrm{ab}}$ & $92.6 \pm 2.2^{\mathrm{abc}}$ & $78.3 \pm 1.7^{\mathrm{ac}}$ \\
13 & $229.6 \pm 5.1^{\mathrm{a}}$ & $187.6 \pm 8.2^{\mathrm{ab}}$ & $276.2 \pm 7.1^{\mathrm{abc}}$ & $224.2 \pm 7.1^{\mathrm{bc}}$ \\
18 & $346.0 \pm 11.0^{\mathrm{a}}$ & $272.0 \pm 13.0^{\mathrm{ab}}$ & $392.0 \pm 12.0^{\mathrm{abc}}$ & $336.0 \pm 12.0^{\mathrm{bc}}$ \\
\hline 2 & $481.0 \pm 59^{\mathrm{a}}$ & $424 \pm 17^{\mathrm{ab}}$ & $614 \pm 78^{\mathrm{abc}}$ & $491 \pm 18^{\mathrm{bc}}$ \\
\hline
\end{tabular}

* Mean $(\bar{x}) \pm$ standard deviation (SD). The values of groups marked with the same superscript are significantly different $(\mathrm{P}<0.05)$

Clinicochemical results. Mean blood plasma Ca concentration was the lowest in the infected chickens out of the four groups compared, at all times except on Day 13. Inorganic P content of the blood plasma was markedly, and in most cases (e.g. on Days 5, 7 and 13) significantly, lower in the infected chickens than in chickens of the other groups at all times of testing except on Days 18 and 22 (Table 5). As regards the vitamin $\mathrm{D}_{3}$ content of the blood plasma of chickens killed on Day 13 (Table 6), it is surprising that vitamin supplementation did not increase the plasma vitamin $\mathrm{D}_{3}$ level of the infected chickens, which was slightly lower than that of the control birds if a single outstanding value of the latter was disregarded. Chickens treated with the irradiated intestinal homogenate developed a surprisingly high vitamin $\mathrm{D}_{3}$ level. The lowest values of bone ash content (Table 7), which is considered to be the best indicator of bone mineralization, were measured in the infected group. The bone ash values obtained in chickens treated with the irradiated inoculum and in those given vitamin $\mathrm{D}_{3}$ supplementation did not differ from each other, while the values of the control group tended to decrease with age. This finding, in line with the histopathological changes seen in the different organs, suggests that the control chickens could become infected by the unknown agent during the experiment because of their inadequate isolation. This may explain the slower body mass gain and lower blood vitamin $\mathrm{D}_{3}$ content of the control group as compared to the group treated with the sterilised homogenate. 
Table 5

$\mathrm{Ca}$ and inorganic $\mathrm{P}$ content of the blood plasma (Experiment II)

\begin{tabular}{|c|c|c|c|c|c|}
\hline Day & $\mathrm{n}$ & Control chickens & 'Infected' chickens & $\begin{array}{l}\text { Chickens treated } \\
\text { with irradiated } \\
\text { inoculum }\end{array}$ & $\begin{array}{c}\text { Chickens receiving } \\
\text { vitamin } \mathrm{D}_{3} \\
\text { supplementation }\end{array}$ \\
\hline \multicolumn{6}{|c|}{ Ca content $(\mathrm{mmol} / \mathrm{l})$} \\
\hline 5 & 3 & $2.27 \pm 0.17$ & $2.20 \pm 0.29$ & $2.36 \pm 0.27$ & ND \\
\hline 7 & 6 & $2.38 \pm 0.17^{\mathrm{a}}$ & $2.10 \pm 0.26^{\mathrm{ab}}$ & $2.18 \pm 0.20^{\mathrm{b}}$ & ND \\
\hline 13 & 5 & $2.23 \pm 0.27$ & $2.25 \pm 0.25$ & $2.33 \pm 0.20$ & $2.16 \pm 0.39$ \\
\hline 18 & 6 & $2.21 \pm 0.26^{\mathrm{a}}$ & $1.95 \pm 0.26^{\mathrm{bc}}$ & $2.62 \pm 0.18^{\mathrm{ab}}$ & $2.72 \pm 0.21^{\mathrm{ac}}$ \\
\hline 22 & 6 & $2.52 \pm 0.31^{\mathrm{a}}$ & $2.07 \pm 0.50^{\mathrm{ab}}$ & $2.60 \pm 0.18^{\mathrm{b}}$ & $2.44 \pm 0.24^{\mathrm{a}}$ \\
\hline \multicolumn{6}{|c|}{ Inorganic $\mathrm{P}$ content $(\mathrm{mmol} / \mathrm{l})$} \\
\hline 5 & 3 & $2.18 \pm 0.07$ & $1.70 \pm 0.06^{\mathrm{a}}$ & $2.23 \pm 0.36^{\mathrm{a}}$ & ND \\
\hline 7 & 6 & $1.90 \pm 0.42^{\mathrm{a}}$ & $1.46 \pm 0.40^{\mathrm{ab}}$ & $1.75 \pm 0.20^{\mathrm{b}}$ & ND \\
\hline 13 & 5 & $1.89 \pm 0.16^{\mathrm{a}}$ & $1.56 \pm 0.42^{\mathrm{ab}}$ & $1.84 \pm 0.18^{\mathrm{b}}$ & $1.72 \pm 0.21$ \\
\hline 18 & 6 & $1.62 \pm 0.16$ & $1.61 \pm 0.57$ & $1.70 \pm 0.14$ & $1.66 \pm 0.15$ \\
\hline 22 & 6 & $1.95 \pm 0.43$ & $1.81 \pm 0.25$ & $2.06 \pm 0.27$ & $2.00 \pm 0.24$ \\
\hline
\end{tabular}

The values of groups marked with the same superscript $(a, b, c)$ are significantly different $(\mathrm{P}<0.05)$. $\mathrm{ND}=$ no data

\section{Table 6}

Blood plasma 25-hydroxy $\mathrm{D}_{3}$-vitamin levels $(\mathrm{ng} / \mathrm{ml})$ on Day 13 of Experiment II

\begin{tabular}{lcccc}
\hline & $\begin{array}{c}\text { Control chickens } \\
(\mathrm{n}=5)\end{array}$ & $\begin{array}{c}\text { 'Infected' chickens } \\
(\mathrm{n}=5)\end{array}$ & $\begin{array}{c}\text { Chickens treated } \\
\text { with irradiated } \\
\text { inoculum } \\
(\mathrm{n}=5)\end{array}$ & $\begin{array}{c}\text { Chickens receiving } \\
\text { vitamin } \mathrm{D}_{3} \\
\text { supplementation } \\
(\mathrm{n}=5)\end{array}$ \\
\hline Mean & 0.41 & $0.224^{\mathrm{a}}$ & $0.52^{\mathrm{ab}}$ & $0.185^{\mathrm{b}}$ \\
SD & 0.267 & 0.52 & 0.158 & 0.062
\end{tabular}

The values of groups marked with the same superscript $(a, b, c)$ are significantly different $(\mathrm{P}<0.05)$

Table 7

Ash content (\%) of the defatted tibia (Experiment II)

\begin{tabular}{|c|c|c|c|c|c|}
\hline Day & $\mathrm{n}$ & Control chickens & 'Infected' chickens & $\begin{array}{l}\text { Chickens treated } \\
\text { with irradiated } \\
\text { inoculum }\end{array}$ & $\begin{array}{c}\text { Chickens receiving } \\
\text { vitamin } \mathrm{D}_{3} \\
\text { supplementation }\end{array}$ \\
\hline 13 & 5 & $51.9 \pm 1.1 *^{\mathrm{a}}$ & $48.1 \pm 1.87^{\mathrm{ab}}$ & $52.3 \pm 1.87^{b}$ & $53.2 \pm 1.59^{b}$ \\
\hline 18 & 6 & $49.0 \pm 3.6^{\mathrm{a}}$ & $42.6 \pm 2.1^{\mathrm{ab}}$ & $53.2 \pm 3.86^{\mathrm{b}}$ & $52.6 \pm 2.1^{b}$ \\
\hline 22 & 6 & $46.1 \pm 4.26^{\mathrm{a}}$ & $43.5 \pm 3.0^{\mathrm{b}}$ & $53.2 \pm 1.6^{\mathrm{ab}}$ & $53.6 \pm 0.87^{\mathrm{ab}}$ \\
\hline
\end{tabular}

* Mean \pm SD; The values of groups marked with the same superscript $(a, b, c)$ are significantly different $(\mathrm{P}<0.005)$ 
Trypsin and protease activities were highly significantly while amylase and lipase activities were moderately significantly decreased in the small intestinal mucosa of the infected chickens compared to the controls (Table 8). Amylase and trypsin activity of the pancreas significantly increased while its protease and lipase activity decreased in the infected chickens.

Table 8

Digestive enzyme activities of the pancreas and small intestinal mucosa of control and 'infected' chickens (on Day 13 of Experiment II)

\begin{tabular}{lcccc}
\hline & $\begin{array}{c}\text { Amylase } \\
\text { U/mg protein }\end{array}$ & $\begin{array}{c}\text { Trypsin } \\
\text { mU/mg protein }\end{array}$ & $\begin{array}{c}\text { Protease } \\
\text { mU/mg protein }\end{array}$ & $\begin{array}{c}\text { Lipase } \\
\mathrm{mU} / \mathrm{mg} \text { protein }\end{array}$ \\
\hline Pancreas & & & & \\
Control ( $\mathrm{n}=4)$ & & & & \\
Mean & 13.07 & 94.41 & 328.31 & 51.47 \\
SD & 1.73 & 5.18 & 49.36 & 4.93 \\
'Infected' ( $\mathrm{n}=5)$ & & & & \\
Mean & 28.16 & 136.54 & 218.91 & 37.30 \\
SD & 4.79 & 9.52 & 21.52 & 8.53 \\
$\mathrm{P}<$ & 0.001 & 0.001 & 0.001 & 0.05 \\
\hline Small intestinal mucosa & & & & \\
Control (n=4) & & & & \\
Mean & 1.61 & 52.55 & 510.34 & 39.02 \\
SD & 0.29 & 2.69 & 49.19 & 2.58 \\
'Infected' (n=5) & & & & \\
Mean & 1.14 & 26.27 & 242.34 & 30.16 \\
SD & 0.05 & 3.73 & 22.14 & 4.78 \\
P $<$ & 0.01 & 0.001 & 0.001 & 0.01 \\
\hline
\end{tabular}

\section{Discussion}

The degree of growth retardation of the infected chickens and their variability in size observed during the experiment were highly similar to findings obtained in the field case, although in the latter case specific measurement results were not available. The nature of the ossification disturbance (defective calcification) revealed by gross and histopathological examination, as well as the decrease of bone ash content and blood $\mathrm{Ca}$ and inorganic $\mathrm{P}$ level were also similar to findings obtained in the field case. With the exception of the histopathological changes of the parathyroid, many features of the condition corre- 
sponded to changes seen in a malabsorption syndrome experimentally reproduced in young poults by Perry et al. $(1991 a, 1991 c)$. That syndrome, the aetiology of which is unknown, also manifested itself in skeletal lesions and disturbances of mineral metabolism. The histological changes shown by the chickens' tibia at the different times of examination closely resembled those seen in poults after 2 weeks of age. The hypertrophic and ossification layers of the physis widened, the cartilage trabeculae thickened, became uneven and showed defective calcification. These ossification disturbances are similar to the bone pathologies described by Thorp and Waddington (1997) in incipient phosphorus-deficient rickets of broiler chickens.

The condition observed by us could be transmitted and experimentally reproduced with the small intestinal and pancreatic homogenate of the affected chickens. It appears that bacteria or similar microorganisms can be ruled out as agents involved in the aetiology of infectious stunting (Kouwenhoven et al., 1978; Sell et al., 1992). At the same time, our earlier studies suggested that the intake of some chemical (e.g. a virus-induced immunogenic substance or a toxic material of some kind) present in the intestinal homogenate might play a role in the pathogenesis of that syndrome (Rudas et al., 1988). However, the results of Experiment II seem to rule out that possibility, since the intestinal homogenate sterilized by irradiation lost its 'pathogenicity'. Namely, high doses of radiation destroy all microorganisms (thus also viruses) but is assumed to leave intact other biologically active substances (immunogenic substances or toxins) present in the homogenate.

The decrease observed in the digestive enzyme activities of the small intestinal mucosa and the pancreas indirectly proves that maldigestion typical of infectious stunting occurs also in the condition studied in this case.

In contrast to observations made by Kouwenhoven et al. (1978) in field cases of runting in broilers, the results of the present Experiment II indicate that by the administration of large doses of vitamin $\mathrm{D}_{3}$ the growth retardation typical of the condition can be ameliorated, blood $\mathrm{Ca}$ and inorganic P levels corrected, and defective mineralization of the developing bones prevented. At the same time, the low 25-hydroxy-vitamin $\mathrm{D}_{3}$ concentration of the blood could not be influenced in that way, which finding is difficult to explain.

The functional role of the parathyroid in the pathogenesis of the condition is very difficult to judge. Namely, while certain authors observed morphological changes indicative of parathyroid hyperplasia (Perry et al., 1991a) or hypertrophy (Reece and Frazier, 1990), in this study we found regressive changes, vacuolar degeneration and fibrosis suggestive of hypofunction, at least up to 2 weeks of age of the infected experimental chickens. The increased phosphate excretion caused, even though indirectly, by enhanced parathyroid hormone secretion presumably associated with parathyroid hyperplasia (Klinefelter et al., 1984) may 
be one of the possible explanations of the decreased phosphate levels of the blood plasma. At the same time, the parathyroid damage seen by us is indicative of a decreased parathyroid hormone secretion and is inconsistent with the existence of the above-mentioned correlation. Therefore, the possibility arises that, in addition to the lowered blood vitamin $\mathrm{D}_{3}$ level and a possibly defective absorption of $\mathrm{Ca}$ and $\mathrm{P}$, an impairment of parathyroid hormone secretion may also play a role in the pathogenesis of the bone abnormality.

It cannot be excluded that the regressive and the proliferative (hyperplastic) changes occur in the parathyroid in different stages of the pathogenesis of the disease process. This could explain the above apparent contradiction, the more so as others (Perry et al., 1991a) observed parathyroid hyperplasia somewhat later in life (at 21 days old). A reliable elucidation of these questions would require knowledge of the blood parathyroid hormone levels.

Several authors have reported the high incidence of encephalomalacia in connection with infectious stunting (Van der Heide et al., 1981; Kouwenhoven et al., 1983). In this study, pronounced oedema and consequent neuronal damage were recognised in the cerebellum, and sometimes also in the cerebrum, of chickens that died during the field case and of 'infected' chickens killed during the transmission experiments. These changes, however, were somewhat different from those seen in chicken encephalomalacia associated with vitamin E deficiency, as in the case reported by us no microangiopathy accompanied by hyaline thrombus formation and haemorrhages was seen.

As regards the pathogenesis of 'ascites syndrome' that occurred in massive form at 5-7 weeks of age in one of the flocks studied by us, the possible predisposing role of a transient disturbance of phosphorus metabolism (hypophosphataemia) that developed earlier in life may be suggested. This possibility was indicated by the experimental results of other authors (Julian et al., 1986).

Several authors agree that the morphological features of the skeletal abnormality may change within a relatively short time, even in a few days (Perry et al., 1991c), and our results also support this view. According to certain observations, the morphologically distinguishable forms of osteodystrophy, dyschondroplasia and femoral head necrosis may occur within a given flock simultaneously, with a severity varying by animal (Reece and Frazier, 1990). In their experiments with poults, Perry et al. (1991c) found a narrowing of the ossification zone of the tibia, attributed by them to hypocalcaemia, and histological changes indicative of osteoporosis. These changes were typically seen in poults under 2 weeks of age. Subsequently, however, widening of the ossification zone like that typically seen in rickets was observed. In our opinion, for lack of an in-depth knowledge of the time-course of absorptive and hormonal changes, the cause and pathogenesis of this phenomenon cannot be fully elucidated and explained at present. 
According to the routine diagnostic practice applied by us earlier, in chickens over 2 weeks of age the diagnosis of infectious stunting was established on the basis of growth retardation, variation in size, defective and abnormal feathering, and a combined evaluation of the characteristic gross and histopathological changes (small intestine containing undigested feed, caeca with frothy, foulsmelling content, degenerative changes, inflammation and fibrosis in the pancreas, myocarditis). However, based upon the results of the present experiment and similar observations made by others (Vertommen et al., 1980), this diagnostic practice needs to be revised, since infectious stunting also has clinical manifestations dominated by the disturbance of mineral metabolism.

\section{Acknowledgements}

We wish to thank Emma Kósa for the determination of digestive enzyme activities, Mária Csörögi for clinicochemical assays of the blood samples, and János Bariska for the measurement of blood vitamin $\mathrm{D}_{3}$ levels.

\section{References}

Angel, C. R. and Sell, J. L. (1990): Stunting syndrome in turkeys: Physical and physiological changes. Poultry Sci. 69, 1931-1942.

Bergs, G. H. H. and Goedegebuure, S. A. (1982): 'Runting and leg weakness' and 'lesions of the femur' in broilers. Tijdschr. Diergeneesk. 107, 950-957.

Bitay, Z., Povazsán, J., Rátz, F. and Sághy, E. (1986): Diagnostic and epizootiological studies on the infectious stunting disease (malabsorption syndrome) in broilers flocks (in Hungarian, with English abstract). Magyar Állatorvosok Lapja 41, 35-40.

Julian, R. J., Summers, J. and Wilson, J. B. (1986): Right ventricular failure and ascites in broiler chickens caused by phosphorus-deficient diets. Avian Dis. 30, 453-459.

Klinefelter, B. B., Youtz, S. L. and Wideman, R. F. (1984): Effect of parathyroid hormone on total phosphatase and inorganic phosphate in blood, plasma, and urine of domestic fowl. Poultry Sci. 63, 2285-2291.

Kouwenhoven, B., Vertommen, M. and van Eck, J. H. H. (1978): Runting and leg weakness in broilers: Involvement of infectious factors. Vet. Sci. Comm. 2, 253-259.

Kouwenhoven, B., Vertommen, M. and Goren, E. (1983): Runting and stunting syndrome in broilers: The disease with many names and faces. Disease Prevention and Control in Poultry Production, Conf. Austr. Vet. Poultry Assoc., Sydney, pp. 73-79.

Kouwenhoven, B., Vertommen, M. and Goren, E. (1988): Investigations into the role of reovirus in the malabsorption syndrome. Avian Path. 17, 879-892.

McLoughlin, M. F., McLoone, D. A. and Connor, T. J. (1987): Runting and stunting syndrome in turkeys. Vet. Rec. 121, 583-586.

Nelson, T. S., Kirby, L. K., Johnson, Z. B., Halley, J. T. and Beasley, J. N. (1982): Digestion of feed by chicks with pale bird syndrome. Avian Dis. 26, 696-700.

Page, R. K., Fletcher, O. J., Rowland, G. N., Gaudry, D. and Villegas, P. (1980): Malabsorption syndrome in broiler chickens. Avian Dis. 26, 618-624. 
Perry, R. W., Rowland, G. N., Glisson, J. R., Steffens, W. L. and Quinn, J. A. (1991a): Skeletal lesions associated with a naturally occurring poult enteritis. Avian Dis. 35, 158-164.

Perry, R. W., Rowland, G. N. and Glisson, J. R. (1991b): Poult malabsorption syndrome I. Malabsorption in poult enteritis. Avian Dis. 35, 685-693.

Perry, R. W., Rowland, G. N. and Glisson, J. R. (1991c): Poult malabsorption syndrome II. Pathogenesis of skeletal lesions. Avian Dis. 35, 694-706.

Reece, R. L. and Frazier, J. A. (1990): Infectious stunting syndrome of chickens in Great Britain: Field and experimental studies. Avian Path. 19, 723-758.

Reece, R. L., Hooper, P. T., Tate, S. H., Beddome, V. D., Forsyth, W. M., Scott, P. C. and Barr, D. A. (1984): Field, clinical and pathological observations of a runting and stunting syndrome in broilers. Vet. Rec. 115, 483-485.

Rudas, P., Sályi, G. and Szabó, J. (1988): Rapid decrease of the peripheral deiodination of thyroxine in malabsorption syndrome in artificially inoculated broilers. Avian Dis. 33, 279-284.

Ruff, M. D. (1982): Nutrient absorption and changes in blood plasma of stunted broilers. Avian Dis. 26, 852-859.

Sándor, G. and Csörögi, M. (1989): Simultaneous fluorometric determination of vitamins A and E in serum. Acta Vet. Hung. 37, 141-147.

Sell, J. L., Reynolds, D. L. and Jeffrey, M. (1992): Evidence that bacteria are not causative of stunting syndrome in poults. Poultry Sci. 71, 1480-1485.

Szabó, J., Sályi, G. and Rudas, P. (1989): Effect of malabsorption syndrome on pancreatic function in broilers. Poultry Sci. 68, 1553-1560.

Thorp, B. H. and Waddington, D. (1997): Relationships between the bone pathologies, ash and mineral content of long bones in 35-day-old broiler chickens. Res. Vet. Sci. 62, 67-73.

Van der Heide, L., Lütticken, D. and Horzinek, M. (1981): Isolation of avian reovirus as a possible etiologic agent of osteoporosis ('Brittle bone disease'; 'Femoral head necrosis') in broiler chickens. Avian Dis. 25, 847-856.

Vertommen, M., van Eck, J. H. H., Kouwenhoven, B. and van Kol, N. (1980): Infectious stunting and leg weakness in broilers: I. Pathology and biochemical changes in blood plasma. Avian Path. 9, 133-142. 